\title{
MODELLING AND EXPERIMENTAL ANALYSIS OF NOISE TRANSMISSION THROUGH WALL OF A RAILWAY VEHICLE
}

\begin{abstract}
The paper presents results of a grant research project dealing with acoustic properties of the walls and floor of a railway passenger coach investigated by means of the experimental analysis of noise produced during train runs and corresponding simulations. In the research, conditions and theoretical approaches for possible reconstructions of walls and floor of the railway passenger coach using new fibrous-microstructure acoustic materials were defined, with the aim of increasing the sound reduction index. The properties of the proposed materials were compared in terms of the acoustic energy transfer through the porous microstructure calculated by means of simulations. The final acoustic effects of different solutions for the incorporation of the materials in the floor structure and in the complete body of the rail passenger coach were evaluated. In this paper the effects on interior noise of the introduction of a new material for floor and wall are presented.
\end{abstract}

Keywords: Railway vehicle, noise analysis, noise reduction.

\section{Introduction}

In recent years, the environmental aspects of design, operation and maintenance of means of transport have been gaining a high importance on a global scale. Within the European Union, increased attention is being devoted in particular to the reduction of noise generated by railways, as this is one of the main aspects that can hinder the development of this otherwise environmentally-friendly mode of transport [1].

Through its Technical Specifications for Interoperability (TSI) - and in particular through the so-called 'Noise TSI' [2] the EU is systematically pushing towards lower noise emission levels generated by the operation of rail vehicles. The TSI imposes limitations on the generation of noise by rail vehicles passing by, both for new and modified or upgraded rail vehicles. Different values are defined for different types of rolling stock (e.g. for freight wagons, locomotives, multiple units, passenger coaches etc.) and for different operation modes. Therefore most Member States are dealing with rail noise research. In particular the research (e.g. [3]) is focused on technical solutions in the design of railway vehicles (e.g. quieter bogies with new materials, bogie fairings/covers etc.), railway track measures/structures (e.g. rail absorbers, noise barriers, natural walls) and technological aspects of railway operations (e.g. wheel and rail maintenance to reduce roughness).
They all can effectively reduce the noise emitted by operation of rolling stock.

Another important aspect is interior noise. This aspect has seen less attention by the scientific community (e.g. [4 - 7]). There are important implications of interior noise that are bringing this aspect to the forefront in terms of research attention:

- its effects on the attractiveness of rail transport - a still quieter interior can contribute to modal shift towards the rail mode;

- its effects on the health and safety of on-board staff - see e.g. TSI Noise requirement for the driver's cab.

At the same time the use of modern materials and technologies that effectively encourage recycling has special significance in terms of its contribution to interior noise reduction.

The structural design of a vehicle is highly influenced by the properties of its materials and structures. Currently, in the design of vehicles the theory of multi-layer separating structures is being used [8]. So-called sandwich structures are gaining increased usage in the design of rolling stock (Fig. 1). Many advantages of sandwich structures, such as the possibility to use new materials offering the required performance with a lower weight, have led to a wider use of such structures particularly for new vehicles. The characteristics describing the behaviour of sandwich structures are generally consistent with those of composite materials for thin structures that are under development, simply due to the fact

\footnotetext{
* 'Peter Zvolensky, ${ }^{1}$ Juraj Grencik, ${ }^{1}$ Lubomir Kasiar, ${ }^{1}$ Peter Volna, ${ }^{2}$ Riccardo Licciardello

${ }^{1}$ Department of Transport and Handling Machines, Faculty of Mechanical Engineering, University of Zilina, Slovakia

${ }^{2}$ Universita degli Studi di Roma „La Sapienza“, DICEA Dipartimento di Ingegneria Civile, Edile e Ambientale, Roma, Italy

E-mail: peter.zvolensky@fstroj.uniza.sk
} 
that the orientation of the sandwich materials in the correct plane provides the required bending stiffness.

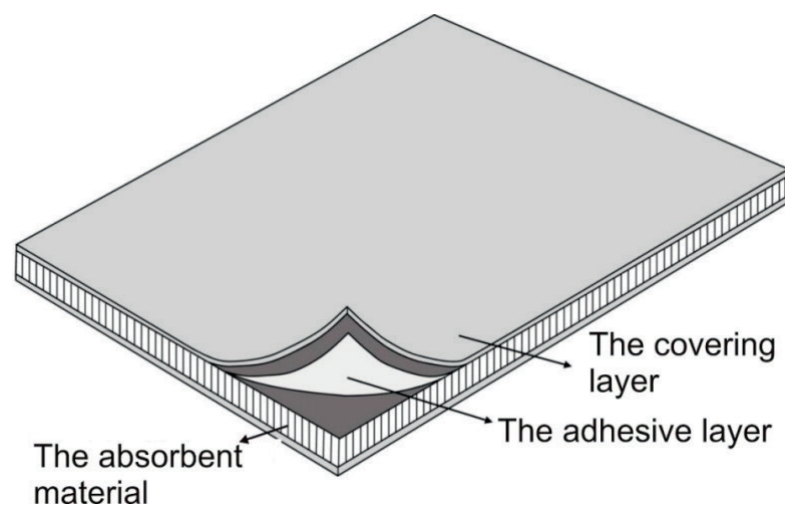

Fig. 1 Scheme of honeycomb sandwich panel [9]

The advantage of sandwich structures is relatively simple possibility of achieving the required parameters without complicated design solutions, using appropriate materials and their appropriate combination, thickness, fibre orientation of the fibrous or composite material also by properties of coatings layers of sandwiches. Sandwich structures offer us a wide range of structural design solutions. For this reason, they are currently widely used in the construction of rolling stock, where it is necessary to achieve especially the desired stiffness of structure and also excellent thermal insulation and acoustic properties [10].

\section{Possibilities for reduction of interior noise in railway passenger wagons}

Generally three sources of noise are considered as the most important for interior noise [8]:

- propulsion system noise,

rolling noise,

aerodynamic noise.

Although the roughness and surface irregularities of wheel and rail are the main sources of rolling noise, in Table 1 other parameters and their potential impact on the noise emitted by a rail vehicle run are shown. Information in the table is based on long-term research of the dynamic effects of track on noise emitted by rolling stock and are based on the European standard EN ISO 3381: 2011 [11]. The data apply to conventional track systems. As shown in the table, the behaviour of the rails pads and mounting of the rail can significantly affect the magnitude of noise emitted. These factors may contribute to an increase of the noise level by up to $6 \mathrm{~dB}$. Therefore it is necessary to clearly describe the type of rail mounting for any type of track (EN ISO 3381:2011).

\section{Application of simulation methods for reducing interior noise level of passenger vehicles}

The purpose of simulation tools is modelling with the aim of the best possible proximity to the actual physical processes. Simulation software tools work on the basis of mathematical models, which are mainly derived from empirical relationships based on a sufficient number of relevant experiments.

Main influence of parameters on the noise emitted by railbound vehicles (EN ISO 3381: 2011) [11]

\begin{tabular}{|l|c|c|c|}
\hline Parameter & $\begin{array}{c}\text { Parameter value for minimum } \\
\text { noise level }\end{array}$ & $\begin{array}{c}\text { Parameter value for maximum } \\
\text { noise level }\end{array}$ & Difference in dB \\
\hline Rail type & UIC 54 E1 & UIC 60 E1 & 0.7 \\
\hline Pad stiffness & $5000[\mathrm{MN} / \mathrm{m}]$ & $100[\mathrm{MN} / \mathrm{m}]$ & 5.9 \\
\hline Pad dissipation factor & 0.5 & 0.1 & 2.6 \\
\hline Sleepers type & concrete & wooden & 1.2 \\
\hline The distance between the sleepers & 0.4 & 0.8 & 0.2 \\
\hline Railway ballast stiffness & $100[\mathrm{MN} / \mathrm{m}]$ & $30[\mathrm{MN} / \mathrm{m}]$ & 0.2 \\
\hline Railway ballast stiffness factor & 2 & 0.5 & 0.2 \\
\hline Displacement of the wheel & $0[\mathrm{~m}]$ & $0.01[\mathrm{~m}]$ & 1.3 \\
\hline Displacement of the rail & $0[\mathrm{~m}]$ & $0.01[\mathrm{~m}]$ & 8.5 \\
\hline Driving wheel profile roughness & smooth & rough & $0.7-3.9$ \\
\hline Rail roughness & smooth & rough & 9.4 \\
\hline Speed & $80[\mathrm{~km} / \mathrm{h}]$ & $160[\mathrm{~km} / \mathrm{h}]$ & 1.1 \\
\hline Axle load & $25 \mathrm{t}$ & $10 \mathrm{t}$ & 0.2 \\
\hline Air temperature & $10^{\circ} \mathrm{C}$ & $30^{\circ} \mathrm{C}$ & \\
\hline
\end{tabular}


These tools require specific inputs to describe material characteristics. In this paper, oak wood, mineral wool and the newly developed material (in the paper entitled NUEM - New Unconventional Environment-friendly Material) are addressed, given their influence on the sound reduction index of rail coach floor/wall structures.

Mineral wool and NUEM are porous materials with a fibrous microstructure. The sound waves propagate through the fibrous material in the air contained in the pores. The acoustic energy is converted mainly into thermal energy in two ways [12 - 13].

1. Surface friction occurs between the particles of air and solid walls of pores and channels, which are located between the pores and connect them.

2. The air pocket permeating through this microstructure constantly changes size and shape according to the shape of pores and channels through which it permeates and therefore internal, so-called viscous mutual, friction of air particles occurs. Surface tension and capillary phenomena, similar to liquids can be observed.

Sound propagation in the porous structure is determined by the propagation characteristics of air through pores of the microstructure, and also by vibrations that propagate through the solid structure of the fibrous material, in this case the fibres. An example of the flow of fluid (air) through the porous structure is shown in the following Fig. 2.

Sound propagation in porous substances is addressed by a scientific discipline, so called "porous acoustics" or also "acoustics of porous materials". By defining all the necessary parameters required by the simulation program, it is then possible to create a model of the porous structure of the material and use it for simulating acoustic energy transfer through this structure.

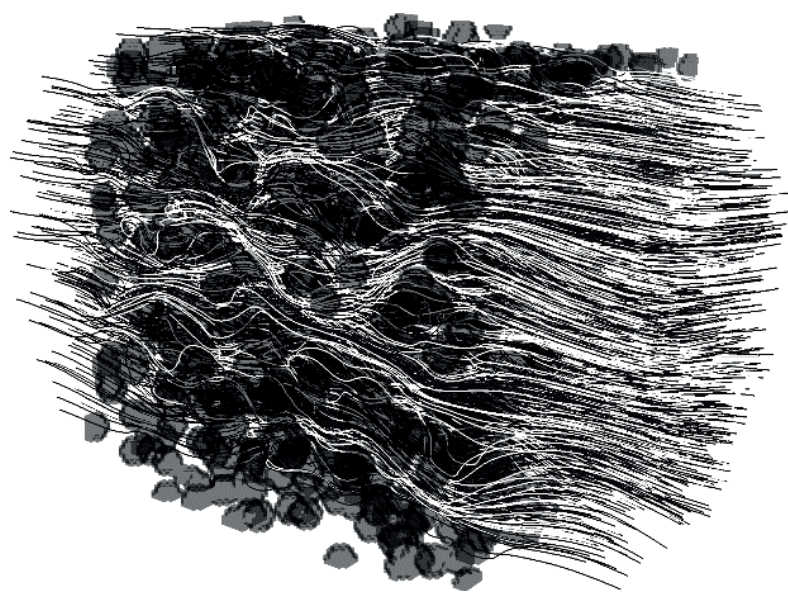

Fig. 2 Permeation of fluid through structure of porous medium [14]

From the research of acoustic properties of porous materials, it turns out that the viscous characteristic length $L_{v}$ has the most significant impact on acoustical parameters, such as sound absorption and sound reduction index. It is a parameter which determines the mean value of the macroscopic dimensions of the channels connecting the individual pores of the material structure. Here viscous losses of sound energy occur by air pressure changes when permeating from one pore to another

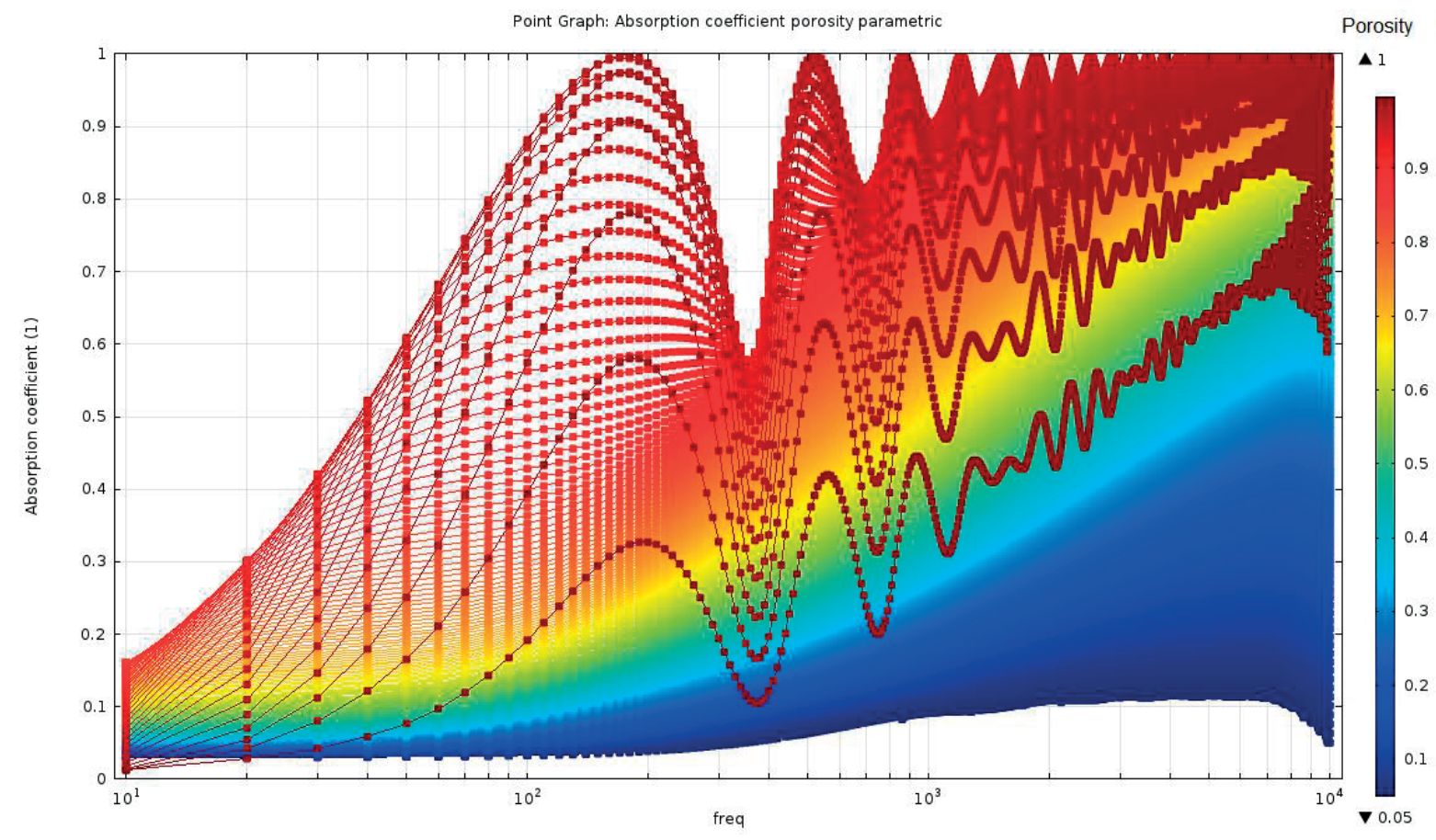

Fig. 3 Frequency dependence of the sound absorption coefficient on the porosity of the fibrous material [18] 


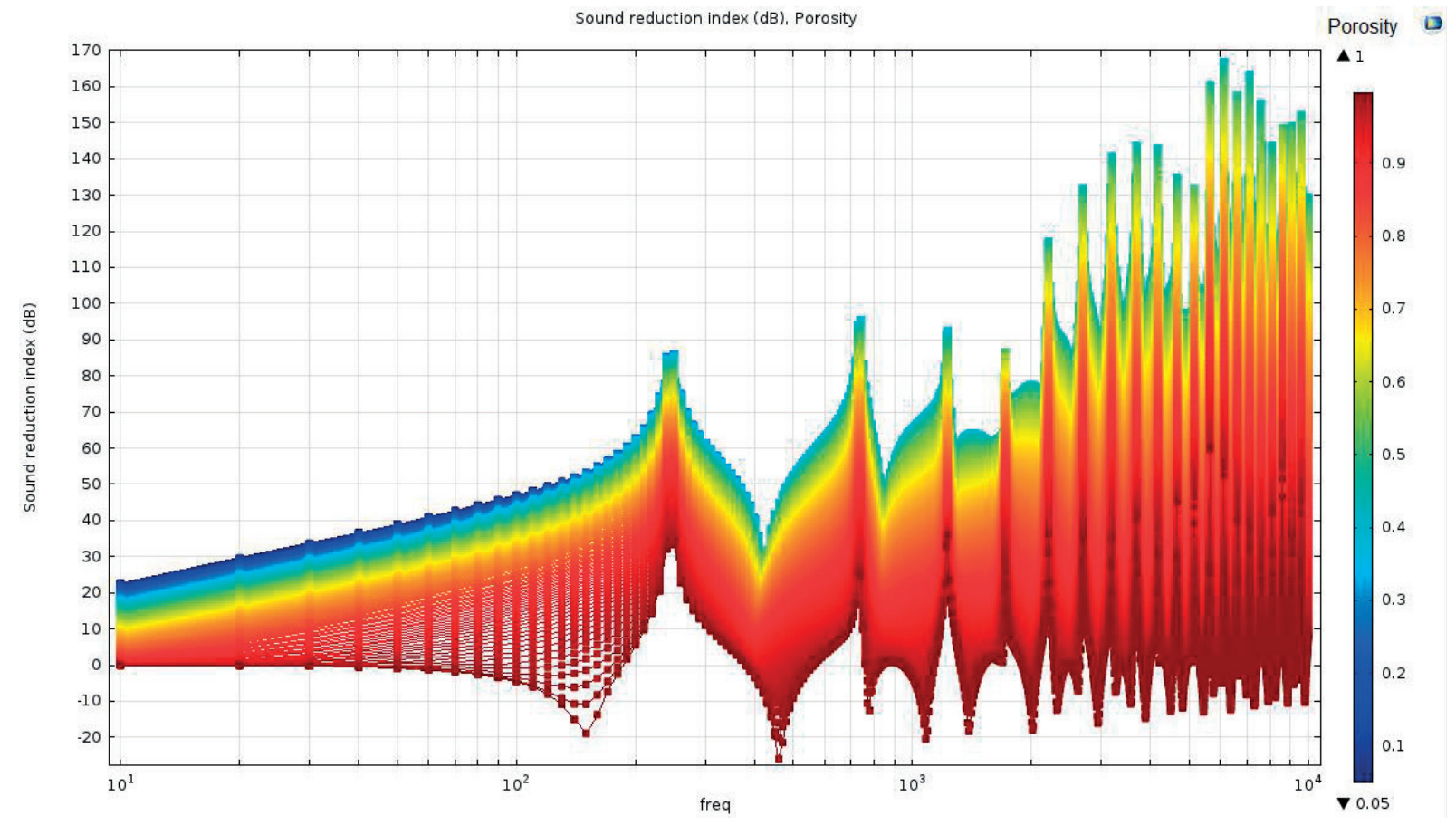

Fig. 4 Frequency dependence of the sound reduction index on the porosity of the fibrous material [18]

through a channel that connects these pores. From the viscous characteristic length a parameter called thermal characteristic length $L_{t h}$ is derived. It indicates a mean value of a macroscopic dimension of the pores of the porous structure. In these locations of the porous material, surface friction between the air particles and the pore solid surface structure occur and sound energy is converted into heat.

As mentioned above, in the simulation environment a number of mathematical models for the calculation and simulation of the transfer of acoustic energy through porous structure

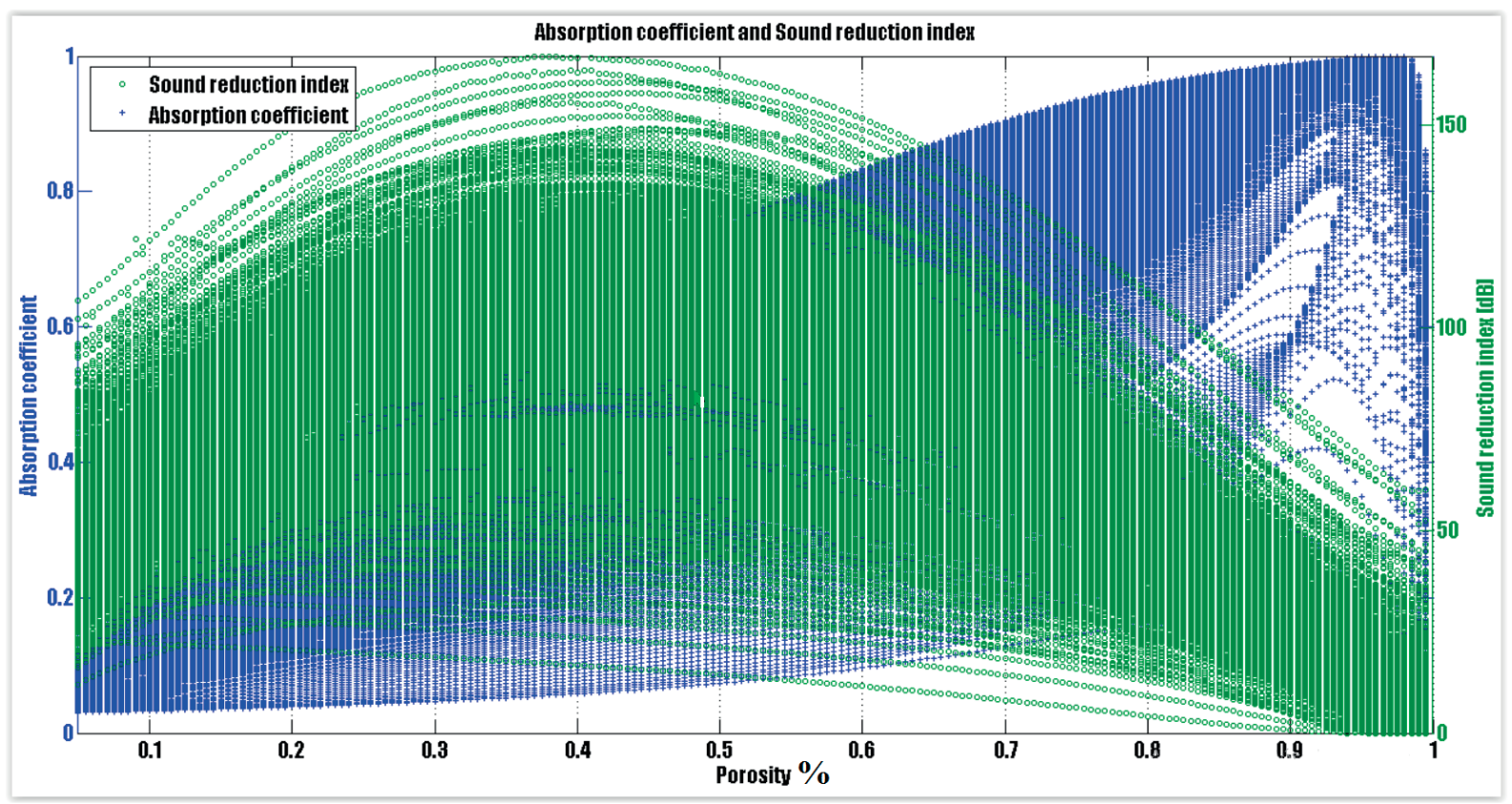

Fig. 5 Chart showing frequency dependencies of investigated parameters [18] 
are in use. The most commonly used mathematical models are, for example, the Delany-Bazley-Miki model [15] and the Johnson Champoux Allard (JCA) model [16]. For simulation in COMSOL software, when solving the problems with porous materials, the JCA model (Johnson-Champoux-Allard) is used, which works on the principle of filling the pores. Their shape can be adjusted in this model to achieve good accuracy while maintaining the calculation time. (Most often a cylindrical tube is set with defined diameter, height and number of pores)

The JCA model in the simulation environment COMSOL Multiphysics 5.0 [17] was used for this research. For the calculations, the frequency range from $10 \mathrm{~Hz}$ to $10 \mathrm{kHz}$ was explored in steps of $10 \mathrm{~Hz}$. The calculation was carried out also for changing porosity of the fibrous material. The porosity of the material was varied in the range of $5 \%$ to $99.5 \%$ in increments of $0.5 \%$. The calculation was carried out for each of the defined porosities in this range. In this way, the effects of three parameters - porosity, frequency and sound absorption coefficient (absorption) - were investigated simultaneously. The result is the definition of dependencies shown in the following Figs. 3 and 4.

The data obtained were subsequently processed in MATLAB program and $3 \mathrm{D}$ graphs were drawn showing the dependence of all investigated parameters at the same time. An example is shown in Fig. 5, showing view on 3D graph in the y-axis direction.

The objective of the calculations was to assess the impact of material porosity on its acoustic properties such as the sound absorption coefficient and the sound reduction index in the frequency range of $10 \mathrm{~Hz}$ to $10 \mathrm{kHz}$. The results show that the best combinations of material characteristics are on intersection between absorption coefficient and sound reduction index.

Simulations were then performed to assess the possible use of different materials for floors or walls of a passenger coach with the objective of minimising noise transfer [18].

\section{Noise measurements of train runs and their use for modelling acoustic conditions in the interior of a railway passenger wagon}

The porosity of the investigated porous materials is necessary for specification of an input for the simulation computation. The result of the simulation can indicate the performance of the porous materials used in the body structure of the passenger coach. An excitation signal was used as specific boundary condition. The signal was used for excitation of the coach's floor surface. The signal was obtained by measuring the exterior noise in a modernised railway passenger coach, series Bdghmeer, on the selected railway track sections Prievidza - Leopoldov and Leopoldov - Bratislava Main Station. On each section of rail track a series of noise measurements were performed. The positions of the measurement microphones are shown in Fig. 6. The excitation signal was taken from the measured data ensuring a small effect of dynamic vibrations. The main reason for choosing such signal was the corresponding choice of using an acoustic, not vibro-acoustic, simulation process [19-20].

The measurement was carried out on two types of track. The track section Prievidza - Leopoldov is an old line and train speed during the measurement was $70-80 \mathrm{~km} \cdot \mathrm{h}^{-1}$. The track section Leopoldov-Bratislava main station was run at the speed of 100-110 $\mathrm{km} \cdot \mathrm{h}^{-1}$ as it is a new modernised "corridor" line. On each of the track sections 11 measurements were performed.

Positions of measurement microphones are shown in Fig. 6. Measurement has been carried out using a measuring system Pulse 3560 B Bruel \& Kjær. During the measurements, sound pressure levels and frequency analysis from three measurement microphones were recorded. One measurement time was $60 \mathrm{~s}$. The signal was taken from the measured data with small effect of dynamic vibrations. The main reason for the chosen signal with the small effect of dynamic vibrations was using the acoustic, not vibro-acoustics simulation process [19 - 20].

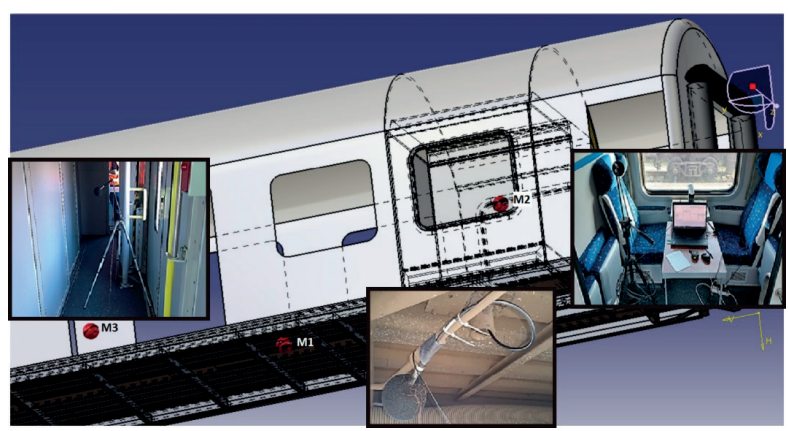

Fig. 6 Position of measurements microphones M1, M2 and M3 [18]

The chosen excitation signal was measured using microphone M1 on the reference section of railway track Bahon - Cifer.

Measurement conditions: [18]

Date of measurement 25.11.2015

Time of measurement

Relative humidity of air $43 \%$

Wind speed, Weather Calm, Sunny

Temperature

$1{ }^{\circ} \mathrm{C}$

Atmospheric pressure

$116 \mathrm{hPa}$

The excitation signal for the body surface excitation is a modified version of the one used for floor surface excitation. The sound pressure level values were reduced by $30 \mathrm{~dB}$ over the 


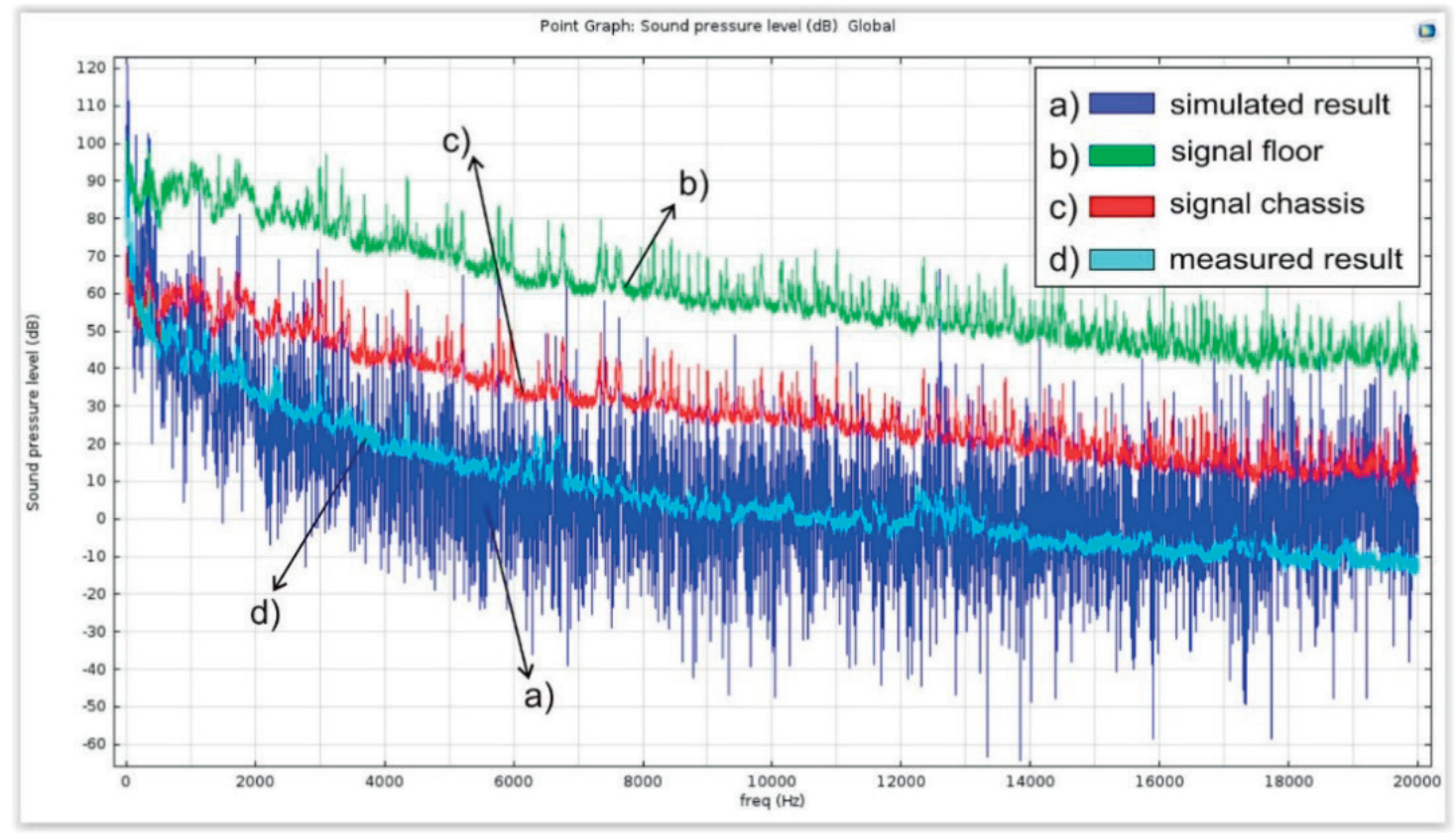

Fig. 7 Comparison of simulation results (a) with measurement results (d), floor excitation signal (b) and body excitation signal (c) [18]

entire frequency range. Excitation signals, measured signal and simulated signal are shown in the following graph (Fig. 7).

Measurements were not only intended to obtain a sufficient number of data necessary for simulation calculation, but also for case studies and identification of impact of track dynamic effects and running speed on the noise emitted by a vehicle.
The simulation and measurements have shown that the replacement of oak wood in the structure of the wooden skeleton with porous material NUEM, is the most effective solution in all investigated applications.

The wooden skeleton is a part of the floor structure. Based on the results of the simulation, the oak wood skeleton is an

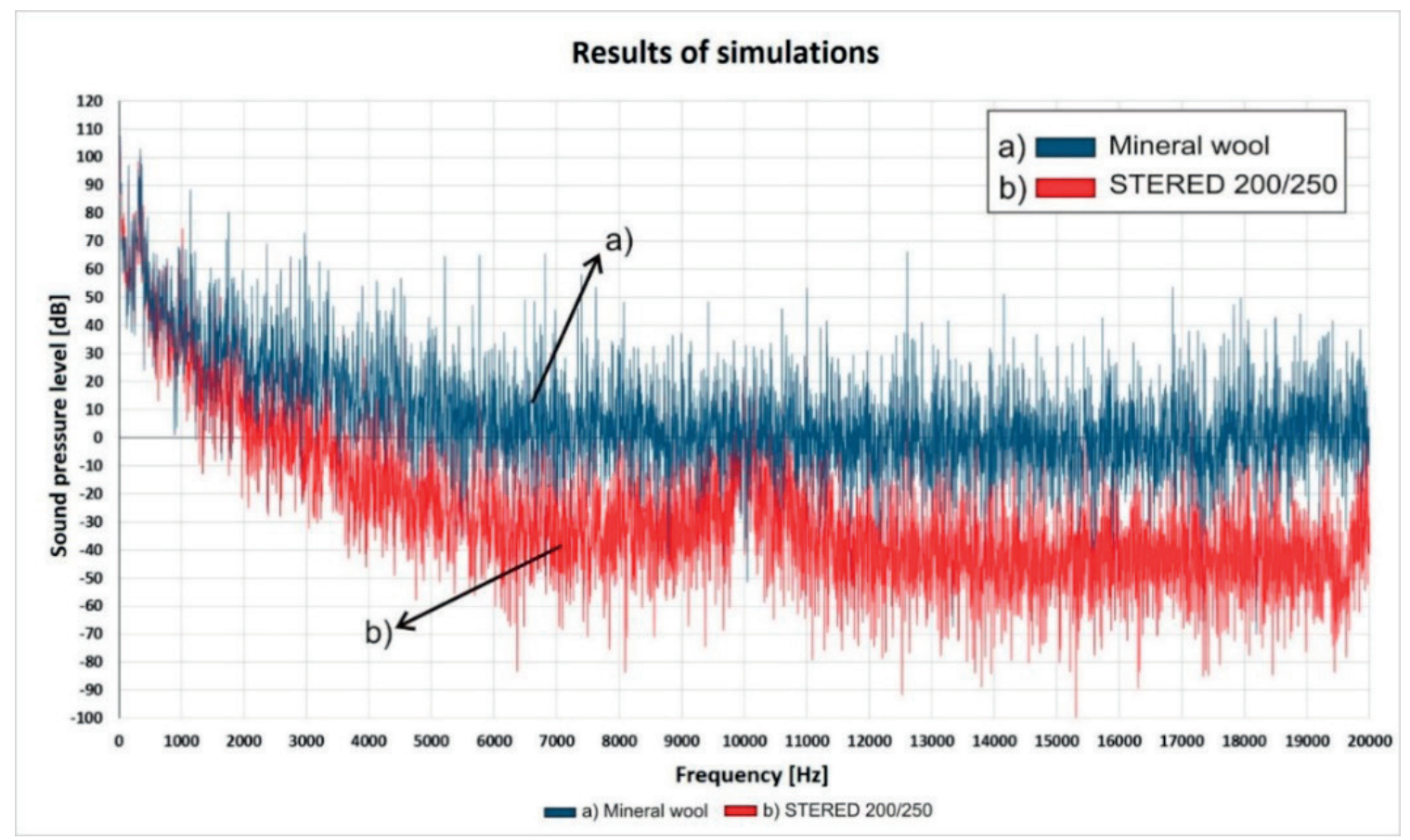

Fig. 8 Comparison of simulation results by using insulating layer made of mineral wool and wooden prism in structure of the floor with results of simulation by using NUEM material as an alternative for wooden prism [18] 
a)

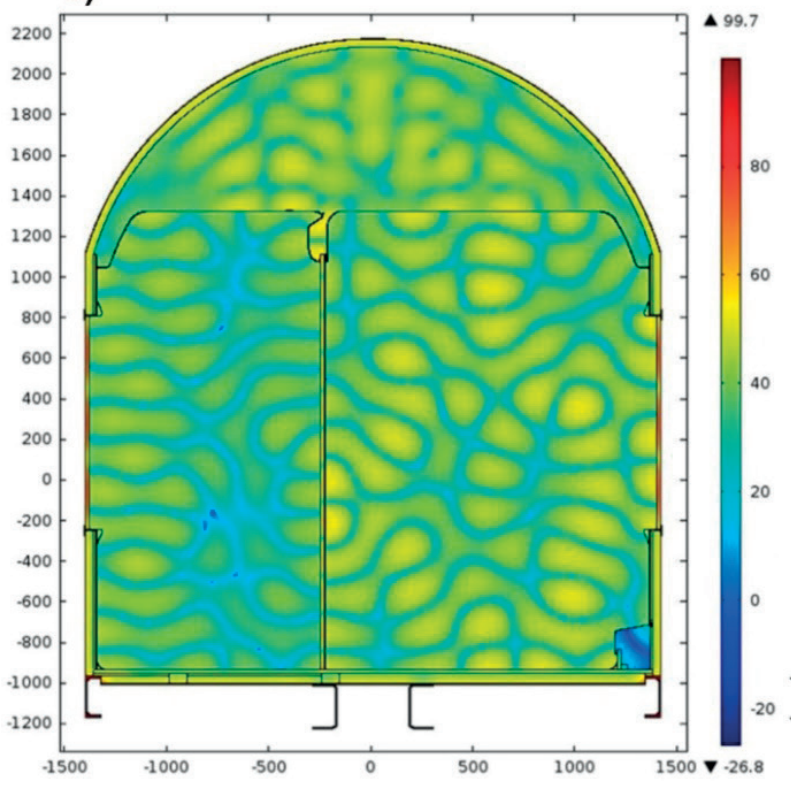

b)

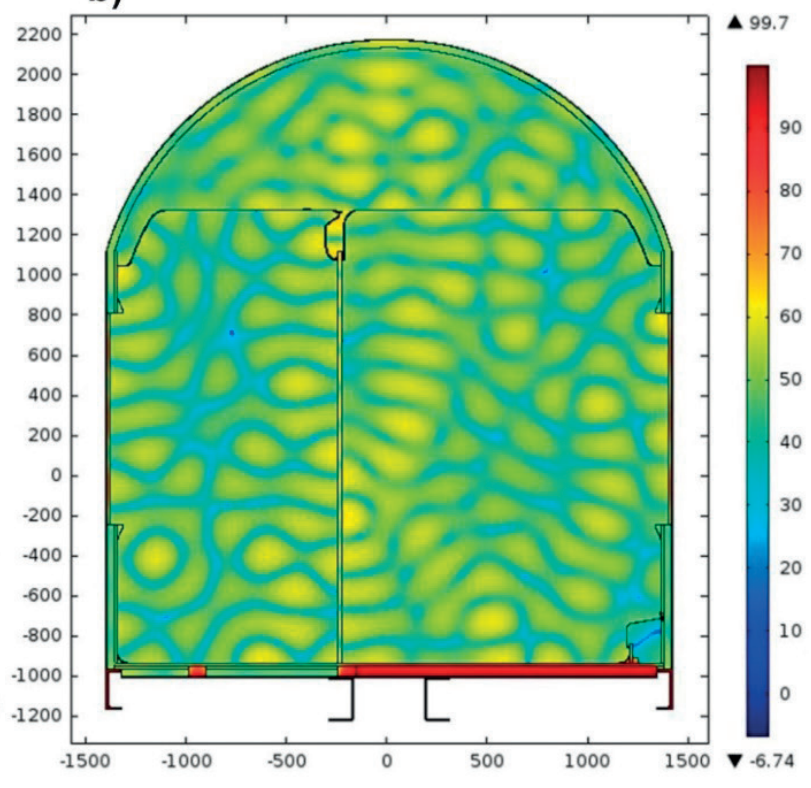

Fig. 9 Comparison of the models corresponding to the current situation and using NUEM material (a) as an alternative for wooden prism (b) [18]

important path for vibro-acoustic energy. This adverse effect of the wooden skeleton was eliminated by using material NUEM. As an example the 2D models are shown and represent a crosssection structure of the car-body, where the position of a wooden prism or wooden skeleton in the structure of the floor is used. The simulation results have shown the effect of using material NUEM as an alternative to the wooden prism.

The simulations allowed the identification of the other part of the coach structure where a significant path of acoustic energy can be observed (Figs. 8 and 9): the window. The window's glass panes were observed to oscillate in a narrow frequency spectrum around $10 \mathrm{kHz}$.

\section{Conclusions}

In the search for suitable technical solutions and methods for noise reduction, it is important to recognise that the suitability of sound absorption materials, or sound reduction materials, depends on the acoustics situation. By using suitable simulation processes it is relatively easy to identify vibro-acoustics paths and sources of acoustic energy. It is important to find technical solutions to eliminate the influence of any identified vibroacoustic path.

For this purpose, an original simulation scheme for sound transfer through the floor and walls of a railway passenger coach was created within this research project. Original simulation results in terms of frequency spectrum sound transitions in the original and new proposed material composition of the floor and walls of a passenger coach were obtained.

Comparison of the simulation models results was carried out in relation to the current situation and to the proposed application of a new porous material - NUEM - in the structural design of the car body. The proposed material seems to be promising sound absorption alternative for the wooden grid in the floor of the coach.

Besides other benefits of the NUEM material, which has been proposed for use in other rail noise-reduction systems, the most significant from the environmental point of view is that the material is obtained by recycling waste from the textile material used for thermal and acoustic insulation in the automotive industry. The base material consists of synthetic fibres with a high resistance against environmental effects. Thus, it can be used even outdoors, and has wide range of applications also for railway infrastructure and track.

Last but not least, noise generated by railway vehicles largely depends on their technical conditions, which are directly related to the proper maintenance system [21].

\section{Acknowledgement}

The research was supported by the Scientific Grant Agency of the Ministry of Education of the Slovak Republic and the Slovak Academy of Sciences in project No. VEGA 1/0766/15 "Research sources of noise emissions from rail transport and ways of their effective reducing". 


\section{References:}

[1] CLAUSEN, U. et al.: Reduction of Noise Pollution from Rail Transport, study, European Parliament, 2012

[2] http://www.era.europa.eu/Document-Register/Documents/IU-Report-on-TSI-RST-NOISE-Annex.pdf

[3] THOMPSON, D. J., JONES, C. J. C.: A Review of the Modelling of Wheel/Rail Noise Generation, J. of Sound and Vibration, 231(3), 2000, 519-536

[4] ZVOLENSKY, P., PULTZNEROVA, A., GRENCIK, J.: The Simulation Calculation of Acoustics Energy Transfer through the Material Structure, MATEC web of conferences: $5^{\text {th }}$ intern. scientific conference Integration, Partnership and Innovation in Construction Science and Education, vol. 86, article No. 04001, 2016, online, ISSN 2261-236X

[5] NEMEC J., RANSDORF, J., SNEDRLE, M.: Noise and its Reduction in Technical Practice (in Czech), 1970, Praha: SNTL

[6] GALliKOVA, J., POPROCKY, R.: Maintenance According to the Technical State with Use of the Enterprise Asset Management Systems, Zeszyty naukowe Instytutu Pojazdow: mechanika, ekologia, bezpieczenstwo, mechatronika, 67-75, ISSN 1642-347X

[7] JOHNSON, D., KOPLIK, J., DASHEN, R.: Theory of Dynamic Permeability and Tortuosity in Fluid-Saturated Porous Media, $J$. of Fluid Mechanics, vol. 176, 379-402.

[8] STRIZ, M., ZVOLENSKY, P.: Possibilities to Reduce Noise from Rail Transport in the EU, TRANS-MECH-ART-CHEM: Moskva: MIIT, 2010, 407-409, ISBN 978-5-7876-0129-9

[9] MERUANE, V.: A Maximum Entropy Approach to Assess Debonding in Honeycomb Aluminum Plates, Entropy, 2014, 28692889), Santiago de Chile

[10] BAVLNA, L., PUlTZNEROVA, A., ZVOLENSKY, P.: Possibilities of Railway Traffic Noise Reduction Depending on the Railway Structure and Construction of the Rail Vehicle, Logistyka, No. 4, 2015, CD-ROM No. 2, 1277-1284, ISSN 1231-5478

[11] EN ISO 3381:2011 Railway applications - Acoustics - Measurement of noise inside railbound vehicles

[12] CHAMPOUX, Y., ALLARD, J.: Dynamic Tortuosity and Bulk Modulus in Air-Saturated Porous Media, J. of Applied Physics, vol. 70, 1975-1979, 21. 51991

[13] MARIA, A., KUCZMARSKI, A., JAMES, C.: Porous Absorption, Johnston Glenn Research Center, Cleveland: Ohio, 1. 2. 2011, www.gearslutz.com: https://www.gearslutz.com/board/attachments/bass-traps-acoustic-panels-foam-etc/185828d1280956359cloud-panel-setup-question-chapter-5-porous-absorption.pt1.c2.s.pdf

[14] MATYKA, M., GOŁEMBIEWSKI, J., KOZA, Z.: The Velocity Distribution in a Random Porous Medium, Proc. of the $5^{\text {th }}$ intern. conference on Porous Media and its Applications in Science and Engineering, Kona: Hawaii, 2014.

[15] MIKI, Y.: Acoustical Properties of Porous Materials Modifications of Delany-Bazley Models, J. Acoust. Soc., Jpn. (E) 11, 1, 1990

[16] JOHNSON, D. L., KOPLIK, J., DASHEN, R.: Theory of Dynamic Permeability and Tortuosity in Fluid-Saturated Porous Media, J. Fluid Mech., 176, 1987, 379-402

[17] COMSOL, P.: Multiphysics Release Notes, COMSOL, November 2013

[18] BAVLNA, L.: Research of Internal Noise in Vehicles on Depending Floor Structure of Rail Passenger Carriage, [Dissertation thesis], Zilina: SjF ZU, 2016, 124 p.

[19] GARCIA, R. E.: Introduction to the Materials Science of Rechargeable Batteries. Tortuosity and Porosity - Tortuosity in Porous Electrodes, Purdue: Purdue University, 2014.

[20] ORESKY, J., ZIARAN, S.: Noise and Vibration in Practice, Kocovce: Nakladatelstvo STU Bratislava, 2011, $63-66$.

[21] ZVOLENSKY, P., STUCHLY, V., GRENCIK, J., POPROCKY, R.: Evolution of Maintenance Systems of Passenger and Freight Wagons from the ECM Certification Point of View, Communications - Scientific Letters of the University of Zilina, vol. 16, No. 3A, 2014, 40-47, ISSN 1335-4205. 